\title{
Evaluation of genotoxicity of acetamiprid using PCR technique on mosquito genome
}

\author{
Mamta Bansal*, Gurjeet K aur and A sha Chaudhry ${ }^{1}$ \\ ${ }^{1}$ Mosquito Cytogenetics Unit, Department of Zoology, Panjab University, Chandigarh-160014, INDIA \\ Department of Community medicine, School of Public Health, PGIMER, Chandigarh-160014, INDIA \\ *Corresponding author. E-mail: mamta_peehu@yahoo.in
}

\begin{abstract}
The present studies deal with the evaluation of the genotoxic potential of acetamiprid at $\mathrm{LD}_{40}$ on a mosquito Culex quinquefasciatus by adopting polymerase chain reaction technique (PCR). This technique was used for detecting DNA damage by amplifying ribosomal DNA internal transcribed spacer 2 (ITS 2) regions. The amplified products were sequenced and the results of treated and non-treated controls were compared using Clustal $\mathrm{W}$ software programme. The results were studied in the form of deletions, additions, transitions and transversions of the bases. The DNA band amplified from control stocks consisted of 444 bases while those from $\mathrm{LD}_{40}$ treated individuals were comprised of 448 bases. The total number of mutations caused in the treated stock was 230 out of which 84 were transitions, 117 transversions, 13 deletions and 16 additions. Thus, it was evident that acetamiprid has a potential to promote gene mutations in the individuals exposed to its semilethal doses.
\end{abstract}

Keywords: Acetamiprid, PCR, ITS 2, Culex quinquefasciatus

\section{INTRODUCTION}

Acetamirpid belongs to the class insecticide and the fairly new family neonicotinoids. The other members of this family are imidacloprid, clothianidin, dinotefuran, nitenpyram, thiacloprid, and thiamethoxam. Neonicotinoids are closely related to the toxin nicotine which is a major component of tobacco plant. They are more toxic to insects and less toxic to mammals, whereby they are considered as ideal pesticides with selective toxicity (Kagabu, 1997; Yamamoto and Casida, 1999).

It is a newest class of insecticides have proved to be ideal alternatives to organophosphates and carbamates (Elbert et al., 1998) with much lower rate of application as compared to traditionally used insecticides (Schmuck, 2001). Acetamiprid is used against sucxking insects, such as aphids and whiteflies on leafy vegetables, cole crops, citrus, cotton, ornamentals and fruiting vegetables. Mammals and humans are exposed to its residues during agricultural practice through skin or when it enters the food chain. Once entered in the body it attacks on the central nervous system of insect by binding of acetylcholine, the major excitatory neurotransmitter in insects to the nAChRs, that further cause excitation and paralysis, followed by the death of the insect. According to US EPA 2002 acetamiprid has relatively low acute and chronic toxicity in mammals with no evidence of carcinogenicity, neurotoxicity, mutagenicity and/or endoctrine disruption. The literature related to its toxicity in any form to target or non target organisms is also very rare. But this pesticide is proven to cause various types of chromosomal aberrations and sister chromatid exchanges in human peripheral lymphocytes culture by Kocaman and Topaktas in 2007 and 2009. This study shows that the exposure to this pesticide may cause genotoxic effects on the target as well as nontarget organisms including man, therefore, the genotoxic evaluation of such pesticides has become a priority area of research. For this, suitable experimental procedures have been successfully adopted. There are a number of techniques to assess the genotoxicity of pesticides on genetic material which involves the use of a number of tests or protocols (Sobels, 1974; Evans, 1977; Gaulden and Liang, 1982; Chaudhry and Anand, 2004, 2005). To evaluate the genotoxicity of chemical compounds and to evaluate DNA damage, there are many new techniques developed like comet assay automatic scoring techniques for micronuclei and ${ }^{32} \mathrm{P}$ - post labeling assay (McKelvey et al., 1993; Pandrangi et al., 1996; Phillips et al., 1997; OCDE, 1998). Some of the recent advances in the field of molecular biology, like gene amplification and DNA fingerprinting with PCR technique, offer new possibilities for detecting DNA damage even at the level of single nucleotide. Jones and Kortenkamp (2000) demonstrated that the genomic alterations in the nucleotide sequence can be detected with PCR assay even if $2 \%$ of the cells are affected by the mutagens. In the present study rDNA internal transcribed spacer 2 (ITS 2) sequence was selected to assess the genotoxic effect of acetamirpid. This spacer lies between $5.8 \mathrm{~s}$ and $28.5 \mathrm{~s}$ rRNA coding ISSN : $0974-9411$ (Print), 2231-5209 (Online) All Rights Reserved ๑ Applied and Natural Science Foundation www.ansfoundation.org 
sequence. It is a phylogenetic marker which is highly conserved within all eukaryotes and carry some of the unique nucleotide sequences of rDNA, therefore any change occurring in them in the form of deletions, additions, transitions and transversions are considered significant. The present set of investigations is a first ever attempt in recording the acetamiprid induced sequence alterations in rDNA domain of Culex quinquefasciatus taken as an experimental insect. For the present set of study $C x$. quinquefasciatus was selected for the reasons like easy availability in nature, short life cycle, rapid rate of reproduction, small diploid no. of 6 chromosomes, lays eggs in group called egg raft. In relevance to this, $\mathrm{LD}_{40}$ of acetamiprid were used in evaluating the mutagenic consequences on the genome of $C x$. quinquefasciatus.

\section{MATERIALS AND METHODS}

Description of pesticide: Acetamiprid ((E)-N- [(6-chliro3-pyridyl)]-N-cyano-N-methyl acetamidine) is commonly sold in the form of white solid powder (Aventis Crop Sciences, U.S.A) under CAS no. 135410-20-7 and molecular formula $\mathrm{C}_{10} \mathrm{H}_{11} \mathrm{ClN}_{4}$ ( Fig. 1) and molecular weight of 222.68. For the present study, $\mathrm{LD}_{40}$ was calculated by probit analysis and were found to be $8.9 \times 10^{-4}$ $\mu 1 / \mathrm{ml}$ (Finney, 1971, Fig. 2).

Collection and rearing of exper imental model: The gravid females of $C x$. quinquefasciatus were collected from village inhabitation Nadasahib along a rivulet, $20 \mathrm{kms}$ East of Chandigarh. They were allowed to lay eggs in water filled petridishes placed in the breeding cages. The egg rafts obtained in this way were allowed to hatch and the larvae were reared on a protein rich diet consisting of a mixture of finely powdered dog biscuits and yeast powder in the ratio of $6: 4$ respectively. A colony was raised under suitable conditions of temperature and humidity in mosquito rearing laboratory (Krishnan, 1964; Singh et al., 1975, Clements, 1994). Fixed number of freshly hatched healthy fourth instar larvae were treated with selected doses of the pesticide by rearing them in acetamiprid containing rearing medium for 24 hours after which they were transferred to pesticide free water and allowed to grow upto adult stages. The desired number of control and treated specimens were processed immediately for DNA extraction while the remaining was preserved in ethanol at $-20^{\circ} \mathrm{C}$ for future use.

DNA extraction: The DNA extraction was carried out as per the standard protocol of Ausubel et al. (1999) with minor modification for mosquito genome by Chaudhry et al. (2006). The integrity of the DNA sample was tested by following the procedure of Sambrook et al. (1989) while the concentration and purity were determined by ultraviolet absorption spectroscopy (Fig. 3). The two specific primers viz: forward primer (FP) 5' -
TGTGAACTGCAGGACACAT-3', and reverse primer (RP): 5' -TATGCTTAAATTCAGGGGGT-3' were used for amplifying the ITS 2 region of the control and treated stocks of $C x$. quinquefasciatus.

DNA amplification: The amplification reactions was prepared by mixing $16.8 \mu \mathrm{l}$ of distilled water, $3 \mu \mathrm{l}$ Taq buffer, $3 \mu$ l DNTP's, $1.2 \mu$ l forward primer, $1.2 \mu$ l reverse primer, $1.2 \mu \mathrm{l}$ Taq polymerase, $1.2 \mu \mathrm{IgCl}_{2}$ and $2.4 \mu \mathrm{l}$ genomic DNA. After loading this reaction mixture in the thermocycler, the reaction was programmed for initial denaturation at $94^{\circ} \mathrm{C}$ for $5 \mathrm{~m}$, followed by 37 cycles of denaturation, annealing and extension at $94^{\circ} \mathrm{C}$ for $1 \mathrm{~m}$, $59^{\circ} \mathrm{C}$ for $1 \mathrm{~m}, 72^{\circ} \mathrm{C}$ for $1 \mathrm{~m}$ respectively followed by one cycle of final extention at $72^{\circ} \mathrm{C}$ for $5 \mathrm{~m}$. The end products of PCR were resolved on 2\% agarose gel containing ethedium bromide dye using $1 \mathrm{X}$ TAE buffer at a constant voltage of $75 \mathrm{~V}$. The gel was visualized over long wave UV transilluminator and photographed using Polaroid camera. A 100 bp DNA ladder (gene ruler) was also run along with all the amplification reactions for calculating the number of base pairs of each band.

\section{RESULTS AND DISCUSSION}

In Fig.4, lane $M$ shows the production of bands of standard DNA gene ruler while lanes A and B show the bands of ITS 2 region of the control and $\mathrm{LD}_{40}$ treated stocks. The bands were sequenced and analysed by using Clustal W software programme. The sequence amplified from the DNA of control stocks consisted of 444 bases while those from $\mathrm{LD}_{40}$ treated individuals were comprised of 448 bases. In the sequence alignment of treated and control individuals of $\mathrm{CX}$. quinquefasciatus the loci marked with asterisk $(*)$ are the regions where bases were identical in the normal and treated mosquitoes while dashes (-) indicate the loci differing due to deletion and additions of bases (Fig. 5). In addition to the places marked with asterisk and dashes, there were some regions which showed differences in the complementary bases in the sequence of the treated mosquitoes. These were the regions where transitions and transversions had taken place. In the $\mathrm{LD}_{40 \text { treated }}$ sequences there were a total of 230 bases which were affected. This included 13 deletions, 16 additions, 84 transitions and 117 transversions (Tables 1,2). As per the details of $\mathrm{LD}_{40}$ treated sequence of ITS

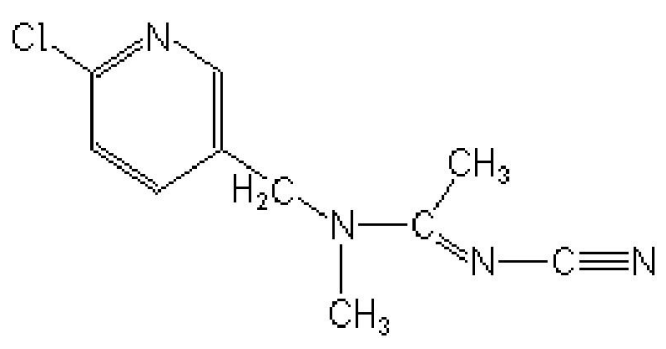

Fig. 1. Structure of acetamiprid. 


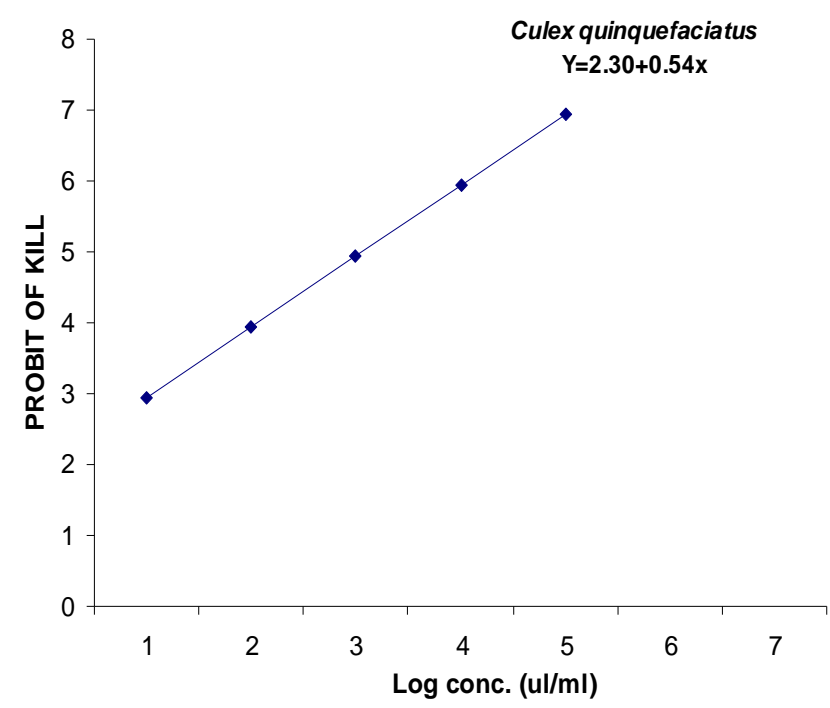

Fig. 2. Relationship between the probit of kill and LD 40 of acetamiprid showing the regression line represented by the equation $Y=a+b x$.

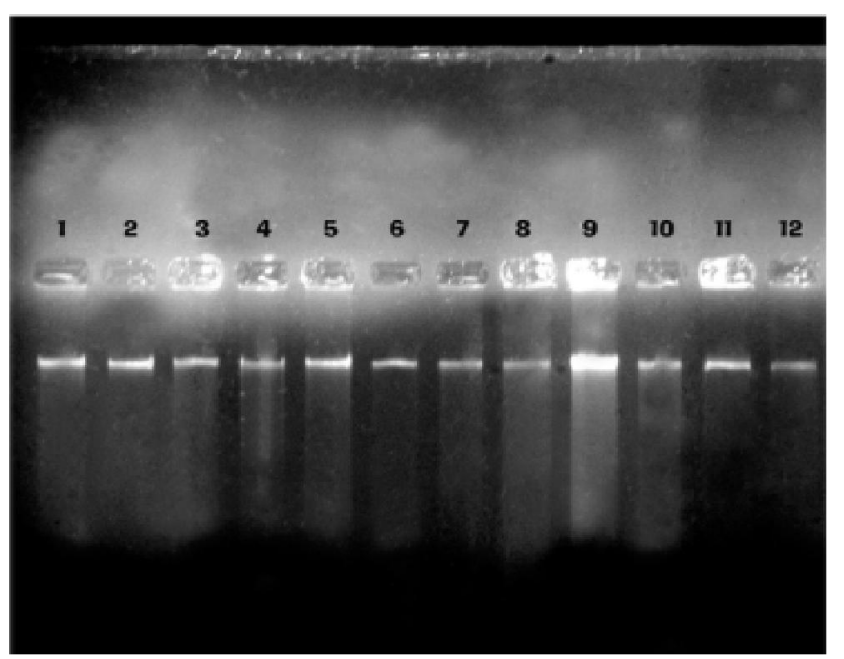

Fig. 3. DNA bands generated from extracted DNA of $C X$. quinquefasciatus of nontreated and LD 40 acetamiprid treated individuals. Lane 1-5: bands from nontreated individuals , Lane 6-12: bands from treated individuals.

Table 1. Aberrations in ITS 2 sequence of $\mathrm{Cx}$. quinquefasciatus individuals treated with $\mathrm{LD}_{40}$ of acetamiprid.

\begin{tabular}{|c|c|c|c|c|}
\hline $\begin{array}{l}\text { Type of } \\
\text { aberration }\end{array}$ & $\begin{array}{l}\text { Total number of } \\
\text { aberrations }\end{array}$ & Bases involved & $\begin{array}{c}\text { Number of } \\
\text { bases }\end{array}$ & Type of bases \\
\hline Deletion & 13 & $\begin{array}{c}1 \\
17 \\
23 \\
50-51 \\
149 \\
292-293 \\
377-381\end{array}$ & $\begin{array}{l}1 \\
1 \\
1 \\
2 \\
1 \\
2 \\
5\end{array}$ & $\begin{array}{c}\mathrm{G} \\
\mathrm{T} \\
\mathrm{C} \\
\mathrm{G}, \mathrm{C} \\
\mathrm{G} \\
\mathrm{C}, \mathrm{G} \\
\mathrm{C}, \mathrm{C}, \mathrm{C}, \mathrm{C}, \mathrm{C}\end{array}$ \\
\hline Addition & 16 & $\begin{array}{c}74-75 \\
86-87 \\
214-215 \\
208-209 \\
345-346 \\
445-448\end{array}$ & $\begin{array}{l}2 \\
2 \\
1 \\
4 \\
3 \\
4\end{array}$ & $\begin{array}{c}\mathrm{C}, \mathrm{G} \\
\mathrm{T}, \mathrm{T} \\
\mathrm{T} \\
\mathrm{A}, \mathrm{G}, \mathrm{G}, \mathrm{C} \\
\mathrm{A}, \mathrm{A}, \mathrm{T} \\
\mathrm{A}, \mathrm{A}, \mathrm{A}, \mathrm{A}\end{array}$ \\
\hline
\end{tabular}

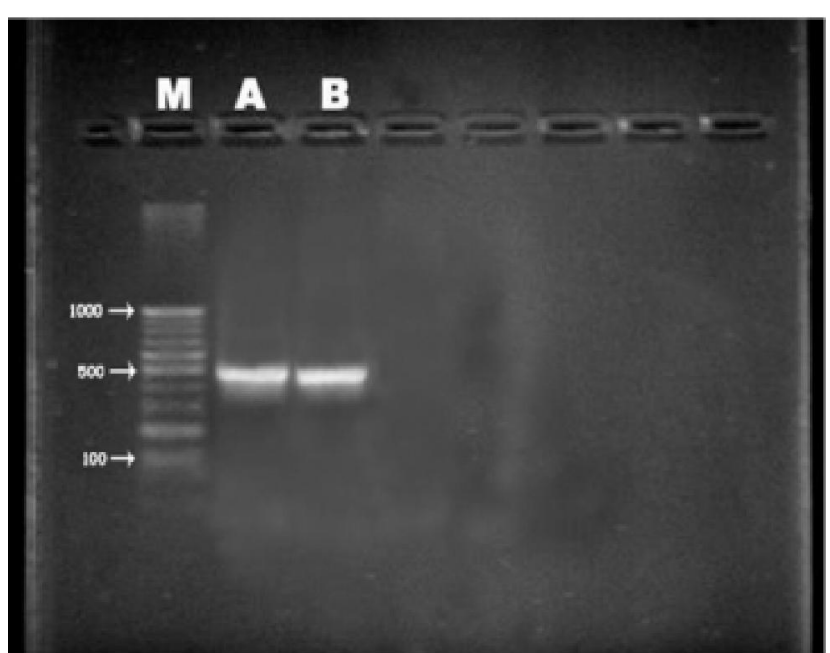

Fig. 4. DNA bands generated from nontreated and acetamiprid $\mathrm{LD}_{40}$ treated individuals of $C X$. quinquefasciatu $L$ ane $M: D N A$ ladder (1000bp),Lane A: Band generated from nontreated individuals, Lane B: Band generated from treated individuals.

2 , there were a total of 13 deletions of bases out of which 5 were in the beginning of the sequence i.e., bases 1,17 , 23 50, 51. There were continues 5 cytosine deleted from base 377-381. In case of transitions, the maximum replacements were encountered from $A^{\prime}$ !G and this number was 35 where the bases were mutated. In case of transversions, the maximum base change were from guanine to cytosine $\left(\mathrm{G}^{\prime} ! \mathrm{C}\right)$ as there were 27 locations of such a change, while thymine to guanine ( $\left.T^{\prime} ! G\right)$ and cytosine to adenine ( $\mathrm{C}^{\prime}$ ! A) were as low as 7 . The average GC percentage of contents of this spacer in $\mathrm{LD}_{40}$ treated individuals was found to be $55.35 \%$, whereas the percentage of AT was $44.64 \%$ (Table 3).

The rate of transversions was higher than transitions. Traditionally, pesticide induced mutations in the integrity of DNA have been studies in the form of numerical and structural changes in the chromosomes, production of micronuclei, errors in the organization and functioning of spindle apparatus, substitutions by base analogues, DNA adducts and dislodging of phosphodiester bonds.

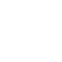

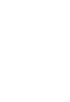


Table 2. Substitutions in ITS 2 sequence of $C x$. quinquefasciatus individuals treated with $\mathrm{LD}_{40}$ of acetamiprid.

\begin{tabular}{|c|c|c|c|c|}
\hline $\begin{array}{l}\text { Type of } \\
\text { aberration }\end{array}$ & $\begin{array}{l}\text { Total number } \\
\text { of aberrations }\end{array}$ & $\begin{array}{l}\text { Type of base } \\
\text { mutated }\end{array}$ & $\begin{array}{l}\text { Total number of } \\
\text { bases mutated }\end{array}$ & Position of bases in the sequence \\
\hline \multirow[t]{4}{*}{ Transition } & \multirow[t]{4}{*}{84} & A-G & 35 & $\begin{array}{c}92,120,124,128,137,160,161,177,180,185 \\
214,215,219,220,317,318,321,350,355 \\
356,357,358,385,387,388,396,397,398 \\
425,426,427,428,429,430,431 .\end{array}$ \\
\hline & & G-A & 22 & $\begin{array}{c}91,94,105,115,125,129,139,141,143,153 \\
154,158,179,205,239,242,244,305,325 \\
440,443,444\end{array}$ \\
\hline & & C-T & 13 & $\begin{array}{c}10,83,90,106,119,127,136,175,191,224 \\
225,283,284\end{array}$ \\
\hline & & $\mathrm{T}-\mathrm{C}$ & 14 & $\begin{array}{c}45,96,145,147,164,206,207,226,250,258 \\
312,313,436,439\end{array}$ \\
\hline \multirow[t]{8}{*}{ Transversions } & \multirow[t]{8}{*}{117} & A-T & 12 & $\begin{array}{c}11,64,93,116,118,121,131,181,190,315 \\
319,415\end{array}$ \\
\hline & & $\mathrm{T}-\mathrm{A}$ & 12 & $\begin{array}{c}70,112,146,210,227,245,246,248,253,417, \\
441,442\end{array}$ \\
\hline & & T-G & 7 & $2,7,65,231,270,271,351$ \\
\hline & & G-T & 21 & $\begin{array}{c}89,95,102,107,110,117,130,132,159,163 \\
171,174,183,188,193,200,202,276,277 \\
280,281\end{array}$ \\
\hline & & $\mathrm{C}-\mathrm{G}$ & 14 & $\begin{array}{c}3,4,5,9,19,20,69,81,223,264,265,268 \\
339,399\end{array}$ \\
\hline & & $\mathrm{G}-\mathrm{C}$ & 27 & $\begin{array}{c}98,113,114,126,133,138,166,168,170,173 \\
192,195,196,197,198,199,201,263,285 \\
286,306,311,341,314,347,433,435\end{array}$ \\
\hline & & $\mathrm{A}-\mathrm{C}$ & 17 & $\begin{array}{c}14,38,82,162,203,209,252,255,260,316 \\
326,329,330,331,334,335,432\end{array}$ \\
\hline & & C-A & 7 & $37,152,157,178,243,400,401$ \\
\hline
\end{tabular}

Some of the recent reprints indicate that exposure to acetamiprid is related to induction of chromosomal aberrations and sister chromatid exchanges in human peripheral lymphocytes at almost all the concentrations and treatment times (Kocaman and Topaktas, 2007, 2009). To the contrary, the test carried out on lower animals like termites showed that even at low dose of $4.8 \mathrm{ppm}$ of acetamiprid, more than $90 \%$ individuals died within 120 $\mathrm{hr}$ of exposure (Mo et al., 2005). Related to such studies on the toxicity of acetamiprid, the larvae of mosquito $C x$. pipiens pallens were also exposed to pesticides, after which the results indicated that these larvae were highly sensitive to acetamiprid as their mortality rate was significantly high as compared to the normal nontreated stocks. The 1 st instar larvae were the most susceptible to acetamiprid as compared to 4th instar larvae which were found to be more tolerant to the action of acetamiprid (Mo et al., 2008). According to El Hassani et al. (2008) and Yassine et al. (2009), field studies showed that acetamiprid was also found to affect the non-target species of insects like honeybees (Apis mellifera). When
Table 3. Sequence characteristics of ITS 2 sequence of $C X$. quinquefasciatus individuals treated with $\mathrm{LD}_{40}$ of acetamiprid.

\begin{tabular}{clc}
\hline S.No. & Character & $\begin{array}{c}\mathrm{LD}_{40} \text { treated } \\
\text { stock }\end{array}$ \\
\hline 1. & Length (Number of bases) & 448 \\
2. & No. of bases mutated & 230 \\
3. & G:C content (\%) & 55.35 \\
4. & A:T content (\%) & 44.64 \\
5. & No. of deletions & 13 \\
6. & No. of insertions & 16 \\
7. & No. of transitions & 84 \\
8. & No. of transversions & 117 \\
\hline
\end{tabular}

the toxicity of acetamiprid was compared with imidacloprid and thiamethoxam among the species of termites it was found that acetamiprid was more toxic than imidacloprid but less toxic than thiamethoxam (Rust and Saran, 2008).

In summation it may be added that polymerase reaction technique is an ideal parameter for evaluating the genotoxic potential of acetamiprid and other pesticides at different dose concentrations which prove harmful to 


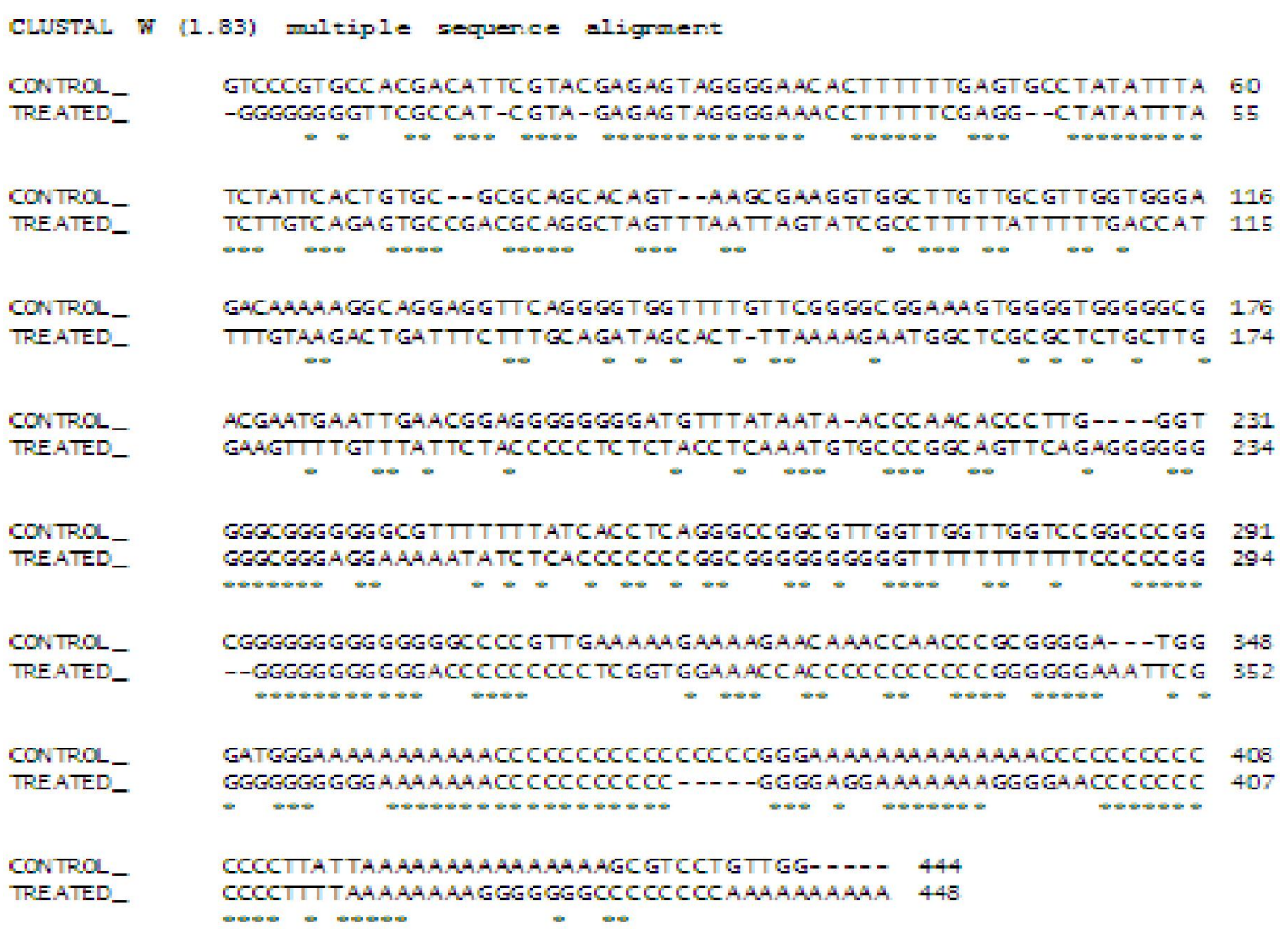

Fig. 5. M ultiple sequence of ITS- 2 sequences of control and $L D_{40}$ acetamiprid treated individuals of $C x$. quinquefasciatus.

the genomic contents of the test organism mosquito. The present study shows that genetic damage caused by such a lower dose of $\mathrm{LD}_{40}$ is so high which further proves the risk of acetamiprid at further higher doses. By study the effect of acetamiprid it was also noticed that the pesticide grossly interfered with the genomic integrity of the cell which lead to the formation of abnormal gametes. As ITS 2 is a regulatory region of the rDNA gene which assists in the function of ribosomal genes, any change in the sequence is expected to automatically effect the coding characteristics meant for the phenotypic and genotypic expressions.

\section{ACKNOWLEDGEMENTS}

The authors are grateful to Chairperson, Department of Zoology and Co-ordinator of Centre of Environment and Vocational Studies, Panjab University, Chandigarh for providing necessary facilities to carry out present research work. The authors are also thankful to the photographic section, Department of Biotechnology for providing necessary facilities to present the photographs.

\section{REFERENCES}

Ausubel. M., Breut, R., Kingston, R. E., Moore, D. D., Sideman, J. G., Smith, J. A. and Struhl, K. (1999). Short protocols in molecular biology. John Wiley and Sons, Inc., London 4: 15- 37.

Chaudhry, A. and Anand, P. K. (2004). Assessment of dominant lethal effects of chlorpyrifos (CPF) using mosquito genetics. Poll. Res., 23 (4) : 767-771.

Chaudhry, A. and Anand, P. K. (2005). Evaluation of the mutagenic potential of chlorpyrifos (CPF) using polytene chromosomes of Anopheles mosquito. J. Environ. Biol., 26(1): 145-150.

Chaudhry, A., Anand, P. K., Geeta, Singh, S. and Lovleen (2006). Ectopic pairing of the intercalary heterochromatin in the organophosphate pesticide treated mosquito chromosomes (Culicidae: Diptera). Cytologia, 71(4): 431-437.

Clements, A. N. (1994). The Physiology of Mosquitoes. Mc Millan and Co., New York.

Elbert, A., Nauen, R. and Leicht, W. (1998). Imidacloprid, a novel chloronicotinyl insecticide: biological activity and agricultural importance. In: Insecticides with novel modes of action: mechanism and application. (Eds. I. Ishaaya and D. Degheele), Springer Verlag, Berlin, Heidelberg, pp. 50-74.

El Hassani, A. K., Dacher, M., Gary, V., Lambin, M., Gauthier, M., and Armengaud, C. (2008). Effects of sublethal doses of acetamiprid and thiamethoxam on the behavior of the honeybee (A pis mellifera). Arch. Environ. Contam. Toxicol., 54: 653-661.

Evans, H. J. (1977). Molecular mechanism in the induction of chromosome aberrations. In: Progress in genetic toxicology. (Eds. D. Scott., B. A. Bridges. and F. H. Sobels), Elsevier/ North Holland Biomedical Press, Amsterdam. pp. 205- 230.

Finney, D. J. (1971). Probit analysis: A statistical treatment of the sigmoid response curve ( $2^{\text {nd }}$ ed.). University Press, Cambridge, pp. 210-225.

Gaulden, M. E. and Liang, J. C. (1982) Insect cells for testing 
clastogenic agents. In: Cytogenetic Assays of E nvironmental Mutagens. (Ed. T. C. Hsu), Allanheld, Osmum, pp. 107-135.

Jones, C. and Kortenkamp, A. (2000). RAPD library fingerprinting of bacterial and human DNA: applications in mutation detection. Teratogen. Carcinogen. Mutagen, 20: 49-63.

Kagabu, S. (1997). Chloronicotinyl insecticides - discovery, application and future perspective. Rev. Toxicol., 1: 75129.

Kocaman, A. Y. and Topaktas, M. (2007). In vitro evaluation of the genotoxicity of acetamiprid in human peripheral blood lymphocytes. Environ. Mol. M utagen, 48: 483-490.

Kocaman, A.Y. and Topaktas M. (2009). The in vitro genotoxic effects of a commercial formulation of $\alpha$-cypermethrin in human peripheral blood lymphocytes. Environ. Mol. Mutagen, 50: 27-36.

Krishnan K.S. (1964). A note on colonization of Culex. Bull WidHilt ORG.31:455-456

McKelvey, U. J., Green, M. H., Schmezer, P., Pool- Zobet, B. L., De Meo, M. P. and Collins, A. (1993). The single cell gel electrophoresis assay (comet assay): A European review. Mutat. Res., 288: 47- 63.

Mo, J., Pan, C., Zhang, S., He, H. and Cheng, J. (2005). Toxicity of acetamiprid to workers of Reticuliter mes flaviceps (Isoptera: Rhinotermitidae), Copotermes formosanus (Isoptera: Rhinotermnitidae) and 0 dontotermes formosanus (Isoptera: Termitidae). J. Pestic. Sci ., 30: 187-191.

Mo, J., Yang, T., Chenf, J and Song, X (2008). Lethal and sublethal effects of acetamiprid on the larvae of Culex pipiens Pallens. Insect Science, 9(3):45- 49.

OCDE (1998). Mammalian erythrocyte micronucleus test. No. 474. In: Addenum to OCD E G uidelines for Testing Chemicals. OCDE, France.
Pandrangi, R., Petras, M., Ralph, S., and Vrzoc. M. (1996). Alkaline single cell gel (comet assay) and genotoxicity monitoring using bullheads and carp. Environ. M ol. Mutagen, 26: 345- 356.

Phillips, D. H. (1997) Detection of DNA modifications by the super ${ }^{32} \mathrm{P}$ - postlabelling assay. M utat. Res., 378: 550554.

Rust, M. K. and Saran, R. K. (2008). Toxicity, repellency, and effects of acetamiprid on western subterranean termite (Isoptera: Rhinotermitidae). J . E con. Entomol., 101(4): 13601366.

Sambrook, J., Fritsch, E. F. and Maniatis, T. (1989). Molecular Cloning: A laboratory manual ( $2^{\text {nd }}$ ed.). Cold Spring Harbor, New York.

Schmuck, R. (2001). Ecotoxicological profile of the insecticide thiacloprid. Pflanzenschutz Nachr Bayer, 54:161-184.

Singh, K. R. P., Patterson, R. S., La-Brecque, G. C. and Razdan, R. K. (1975). Mass raring of Culex pipiens fatigans. Weid. J. Com. Dis., 7: 31-53.

Sobels F.H. (1974). The advantages of D rosophilla for mutation studies. Mutat.Res., 26: 277-284.

U.S. Environmental Protection Agency (USEPA). (2002). Name of chemical: acetamiprid. Reason for issuance: conditional registration.(www.epa.gov/opprd001/factsheets/ acetamiprid.pdf).

Yamamoto, I. and Casida, J. E. (1999). Nicotinoid insecticides and the nicotinic ac etylcholine receptor. Springer-Verlag: Tokyo.

Yassine, A., Adessalam, K., El Hassini, Vincent, G., Catherine, A., Michel, L. and Monoque, G. (2009). Subchronic exposure of honeybees to sublethal doses of pesticides: effects on behavior. Environ. Toxicol. Chem., 28(1): 113-122. 